\title{
Sociedad Chilena de Pediatría Enfrentando el Próximo Decenio
}

\author{
FRANCISCO MORAGA M. ${ }^{1}$, PAUL R. HARRIS ${ }^{2}$ \\ 1. Nutriólogo, Servicio de Pediatría, Hospital San Borja Arriarán. Vicepresidente Sociedad Chilena de Pediatría. \\ 2. Coordinador Comisión de Investigación, SOCHIPE. Unidad de Gastroenterología y Nutrición Pediátrica, División de \\ Pediatría, Facultad de Medicina, Pontificia Universidad Católica de Chile, Santiago, Chile.
}

Frecuentemente solemos acuñar en aforismos lo que estimamos verdades decantadas a través de la historia. Uno de aquellos dice que los hombres pasan y las instituciones permanecen y, como tantos otros, de tanto repetirse impensadamente, termina por perder o equivocar su significado. Que los hombres son transitorios y pasan está claro para todos nosotros, aunque algunos quisiéramos olvidarlo. Pero... ¿las instituciones? ¿Nos referimos con ellas a los edificios, a los nombres, a sus reglamentos o estatutos? Si así fuera, el aforismo sería vacuo y sin sentido. Las instituciones son, en cada determinado momento, los hombres que la integran... en tanto ellos permanezcan ligados a sus antecesores por una comunidad de pensamiento, una línea de acción y un sentido de trascendencia: así expresada, la institución es el espíritu de sus hombres y no la masa de sus instalaciones y reglamentos.

Algunos lo llaman tradición. Nuestra Sociedad Chilena de Pediatría tiene una tradición. Sería soberbia decir que es un Espíritu de excelencia; más realista es enunciarlo como un Espíritu de superación que, con legítima y humana ambición profesional, sueña con la Excelencia. Una tradición basada, más que en el respeto a nuestra normas bien establecidas, en un criterio -similar y compartido por todos nosotros- frente a cada situación o desafío, esto es, en una comunidad de pensamiento.
Quisiéramos compartirla: 88 años, 17 Filiales, 34 Ramas y Comités, 50 Congresos Nacionales y más de 5000 actividades científicas propias y de participación conjunta con otras Sociedades; integrante de varias organizaciones pediátricas internacionales y formando parte de numerosas comisiones y agencias nacionales para el desarrollo de la Pediatría y sus especialidades derivadas. Más de 450 ediciones de nuestra Revista científica y 52 de nuestro magazine; más de un millón y medio de consultas anuales a la edición on line de nuestra publicación científica y más de 500000 visitas a nuestra web. Estas cifras van dando cuenta de la magnitud del trabajo de nuestra Sociedad, y tras ellas aparecen las personas: 49 directivas que, desde aquel lejano 1922, han ido construyendo nuestra organización, cuyo principal propósito y razón de ser lo constituyen sus 2500 socios e integrantes y los aproximadamente 1000 médicos generales, profesionales dedicados a la salud de los niños y adolescentes de nuestro país, a quienes día a día intentamos ofrecer más y mejores vías de acceso a su formación continua, a su desarrollo profesional y a nuevas posibilidades de canalizar sus inquietudes científicas.

Pocas instituciones enfrentan estos desafíos y su historia con la madurez que la nuestra lo hace, abarcando tantas áreas de actividades afines, fomentando el crecimiento sus Filia-

Correspondencia a:

Dr. Paul R. Harris

E-mail: pharris@med.puc.cl 
les, de nuevas Ramas y Comités y motivando a las existentes, incentivando la investigación y la producción científica mediante el financiamiento concursable de proyectos evaluados por una Comisión de Investigación Autónoma, respaldando jornadas, reuniones, congresos, publicaciones, cautelando los fondos generados por las Ramas mediante la profesionalización gerencial y contable, estableciendo alianzas y convenios con el sector privado en un estricto marco ético y un largo etcétera difícil de resumir en una Editorial. Por ejemplo, en el área internacional, nuestra sociedad participa activamente en la Organización de Sociedades Pediátricas del Cono Sur (junto con Uruguay, Bolivia, Argentina y Paraguay), en la directiva de ALAPE (Asociación Latinoamericana de Pediatría) e integrante de la IPA (International Pediatric Association). Y en el ámbito nacional es integrante como fundador y parte del directorio de ASOCIMED (Asociación de Sociedades Científicas Médicas), ASOFAMECH (Asociación de Facultades de Medicina de Chile), CONACEM (Comisión Nacional Autónoma de Certificación de Especialidades Médicas), APICE (Agencia de Acreditación de Programas y Centros Formadores de Especialistas), el capítulo chileno de AGCO (Alianza Global Contra la Obesidad y enfermedades relacionadas), integrando comisiones mixtas como, por ejemplo, la Comisión Mujer, Trabajo y Maternidad en temas relativos a la prolongación del postnatal para favorecer la lactancia y apego, la extensión de la edad pediátrica a los 18 años, reconocimiento de subespecialidades, definiendo estándares de calidad en prestaciones y prestadores AUGE, entre otras muchas organizaciones.

La incorporación de representantes de Filiales en el Directorio, el reintegro de las cuotas sociales a las Filiales mayoritarias siguiendo un criterio subsidiario, la mantención de los Congresos Nacionales en provincias y el fomento a la incorporación informática de cada Filial, son algunas de las iniciativas orientadas a descentralizar nuestro funcionamiento. La renovación de nuestro sitio web, integrado con las redes sociales (facebook, twitter), RSS y facilitando la navegación de sus contenidos mediante un buscador así como la migración a tecnología Open Acces de la Revista Chilena de Pediatría, son avances tecnológicos que apuntan en esta línea: mejorar la comunicación con nuestros socios aprovechando las innovaciones de la internet 2.0. Esto, porque entendemos que las tareas en el desarrollo de la Pediatría nunca se terminan: sólo se cumplen etapas.

En el aspecto científico, hemos realizado este año nuestro Congreso Nacional de Pediatría $\mathrm{N}^{\circ} 50$, alcanzando la cifra record de asistencia de 911 inscritos, los cuales durante 4 días han dado vida al principal evento científico de nuestra Sociedad.

La creación en el año 2008 de la Comisión de Investigación (CI), de funcionamiento autónomo y cuyas principales funciones son la coordinación del Concurso de Proyectos Científicos de la SOCHIPE, ha sido un gran paso en profesionalizar esta actividad. Su responsabilidad principal es asegurar la calidad, transparencia y oportunidad del proceso de evaluación y asignación de los proyectos.

El año 2011 se procederá a renovar los integrantes de los CI, la cual quedará conformada por 2 miembros del Directorio de SOCHIPE y 4 profesionales autónomos de reconocida trayectoria en el campo de Investigación.

El proceso de selección de los trabajos para el Congreso recién pasado, fue exhaustivo y etapificado.

En un primera fase, 2 ó 3 árbitros seleccionados por los encargados de cada rama o comité seleccionó los mejores trabajos de su área, eligiendo $219(70,4 \%)$ trabajos de los 311 recibidos. En este proceso cada rama fue autónoma aun cuando los árbitros contaron con directrices específicas. Es así como los reportes de casos clínicos aislados carentes de novedad no fueron seleccionados este año (51 trabajos rechazados). Adicionalmente, los árbitros seleccionaron $40(6,4 \%)$ trabajos merecedores de postular a premio.

En una segunda fase, la CI permanente, seleccionó los mejores 20 trabajos a ser presentados en la sesión de plenaria y con postulación a premio; 8 trabajos en categoría becados, y 12 en categoría general. Esta segunda fase contó con criterios uniformes y una plantilla de puntuación de 6 ítems con un máximo de 30 puntos. A estos seleccionados, se les solicitó 
un manuscrito extenso de su trabajo, de acuerdo a las bases del concurso.

En la tercera fase, realizada en el Congreso mismo, se caracterizó por la presentación oral de los trabajos con metodología tradicional (exposición 8 min, discusión $3 \mathrm{~min}$ ). Hubo 10 árbitros (miembros del Directorio y de la CI) y se contó con una planilla de 7 ítems con un puntaje máximo de 35 puntos.

Sin embargo, el mayor avance fue en la calidad de los trabajos presentados. Es necesario destacar 4 de ellos con financiamiento Conicyt (Fondecyt, Fonis) y 2 de ellos con otros financiamiento (SOCHIPE, Universidades, Consorcios). Los trabajos destacaron por su buen diseño, análisis estadísticos adecuados, y relevancia de los resultados. De este modo la competencia fue muy ajustada, con mínimas diferencias en la puntuación final. Nuestras felicitaciones a todos los investigadores especialmente a los más jóvenes (becados). Los premiados de este año 2010 se detallan en la tabla 1 . Son ellos y sus trabajos el mejor ejemplo de los que debemos dejar en herencia a la salud de los niños como Sociedad Científica que somos.

Tabla 1. Premios a los mejores trabajos presentados en el 50 Congreso Chileno de Pediatría, Año 2010

\section{Categoría BECADOS}

- Primer lugar: "Relación entre polimorfismos de citoquinas pro-inflamatorias y sus niveles de expresión en la mucosa gástrica de niños infectados por H. pylori" \#223, Francisca Jaime, PUC

- Segundo lugar: "Síndrome metabólico y su asociación con disfunción endotelial medida como Proteína C Reactiva ultrasensible en niños y adolescentes chilenos" \#175, Andrea Godoy Barraza, PUC

- Tercer lugar: "Asociación del estado nutricional materno y peso de nacimiento del recién nacido" \#134, Carlos Flores Berríos, PUC

Categoría GENERAL

- Primer lugar: "¿EEDP O ASQ? ¿Estamos preparados para reemplazar nuestra tradicional evaluación del desarrollo psicomotor por una prueba autoadministrada?" \#020, Luisa Schonhaut Berman, UDD

- Segundo lugar: "Caracterización genética de una población chilena de niños con síndrome nefrótico: del diagnóstico histológico al diagnóstico molecular" \#174, Marta Azócar Pruyas, UCH

- Tercer lugar: "Hiperaldosteronismo Familiar Tipo 1 (Remediable Por Glucocorticoides) En Pacientes Hipertensos Pediátricos Chilenos" \#295, Carolina Loureiro, PUC
Adicionalmente, en Pucón 2010 se entregaron los premios a los mejores trabajos publicados en la Revista Chilena de Pediatría. Nuevamente, la participación de múltiples profesionales (socios y no socios) ha garantizado un proceso arbitrado por pares, expertos en el tema. La Sociedad Chilena de Pediatría cumpliendo sus objetivos fundacionales, ha generado múltiples instancias para fomentar la investigación (concurso de proyectos de investigación, premio a los mejores trabajos ya mencionado, entre otros). Sin embargo, la premiación a los mejores trabajos publicados representa un reconocimiento explícito a los investigadores en la etapa final que es la publicación, ya que los proyectos y mejores trabajos en formato abstract sólo adquieren real importancia cuando llegan a la etapa final de la publicación.

La selección fue realizada por el Comité Editorial de la Revista y evaluó los últimos 6 números publicados previo al Congreso. De este modo se asignaron los premios a los 3 mejores trabajos en categoría general y al mejor trabajo en categoría becados (Premio auspiciado por Nestlé Nutrition). Nuestras sinceras felicitaciones a los autores de cada uno de los trabajos (tabla 2).

Tabla 2. Premios a los mejores trabajos publicados en la Revista Chilena de Pediatría, Año 2009-2010

Categoría BECADOS

- Primer lugar: "Morbilidad y Mortalidad durante el primer año de vida en pacientes con síndrome de Down". Rev Chil Pediatr 2009; 80: 323-331. Natalia Retamal, PUC

- Segundo lugar: "Estado Epileptico no convulsivo infantil". Rev Chil Pediatr 2010; 81: 115-122. Juan Aranguiz, PUC

- Tercer lugar: "Función suprarrenal en pacientes con SBO tratados con corticoides sistémicos (informa preliminar)". Rev Chil Pediatr 2009; 80: 347-353. Francisca Arancibia, PUC

Categoría GENERAL

- Primer lugar: "Evolución de la desigualdad en la mortalidad infantil". Rev Chil Pediatr 2010; 81: 215-220. Mariana Flores, PUC

- Segundo lugar: "Estudios Clínicos Aleatorios en Pediatría de Latinoamérica (1996-2005)". Rev Chil Pediatr 2009; 80: 420-426. Carlos Castillo, INTA/U de Chile

- Tercer lugar: "Validación de un cuestionario autoadministrado para la evaluación del desarrollo psicomotor". Rev Chil Pediatr 2009; 80: 513-519. Luisa Schonhaut, UDD 
Éste ha sido el camino y la riqueza de nuestra Sociedad Chilena de Pediatría: la continuidad histórica, su tradición, su calidad científica, todo ello con las adaptaciones que exigen los tiempos, ha sido y será su fortaleza y su principio orientador. Por ello, la convocatoria a seguir trabajando integrados es un imperativo que nos permite invitarlos a sumarse a la familia que constituye la Sociedad Chilena de Pediatría, para enfrentar los nuevos desafíos que implica entrar al Tricentenario con nuevos bríos en la defensa de los derechos de los niños, a través de acciones que permitan elevar la calidad de los Equipos de Salud enfrentados a la noble y gratificante tarea del cuidado de la infancia y adolescencia.

\section{A LOS AUTORES}

Comunicamos a los autores de los artículos presentados para publicación en Revista Chilena de Pediatría, que ha concluido exitosamente el Proyecto Editorial del Fondo de Publicación de Revistas Científicas CONICYT 2008-2009 "Revista Chilena de Pediatría: De las Publicaciones en Papel a un Proceso Editorial On-Line basado en Open Journal System". Por lo tanto, solicitamos a los autores de los artículos presentados a partir de ahora, que ingresen a www.revistachilenadepediatria.cl, se registren e identifiquen de acuerdo a las instrucciones, y procedan a ingresar su contribución al sistema editorial electrónico según se detalla.

La Sociedad Chilena de Pediatria y Revista Chilena de Pediatría se enorgullecen de poner a disposición de nuestros colaboradores esta moderna herramienta editorial, en forma pionera entre las publicaciones biomédicas de nuestro país.

El Editor 